\title{
THE CO-ORDINATION OF SWIMMERET MOVEMENTS IN THE CRAYFISH, PROCAMBARUS CLARKII (GIRARD)
}

\author{
By G. M. HUGHES* and C. A. G. WIERSMA \\ Biology Division, California Institute of Technology, Pasadena, California $\dagger$
}

(Received 25 February I960)

Many Crustacea are characterized by the use of their appendages for swimming and feeding. In the lower Crustacea both the thoracic and abdominal appendages move for these purposes in a typical metachronal rhythm. The similar rhythmical movements found in the abdominal appendages of the crayfish (Hughes \& Hickey, in preparation) are most probably based on similar nervous mechanisms, but here their function is not so clear. It is probably connected with the increased need for aeration when the animal burrows in mud and, in the female when in 'berry', with the oxygen supply for the developing larvae. The swimmeret movements provide very good material for a study of the general problem of the mechanisms of nervous control of rhythmic limb movements. Few observations have been made on Crustacea from this point of view and the crayfish is very suited for this purpose as considerable information is now available concerning its nervous system (Hughes \& Wiersma, 1960; Wiersma, 1958; Wiersma \& Hughes, 1961). The preparations also proved of interest as in some the influence of stimulating fibres descending from the brain was shown. Clear evidence for the presence of pathways with excitatory or inhibitory effects on the discharge of motoneurones in the abdominal ganglia has been obtained.

\section{MATERIALS AND METHODS}

The crayfish, Procambarus clarkii (Girard), was used throughout the experiments, for many of which females were preferred because five pairs of swimmerets could be observed during the movements. In the male the first two pairs are modified as secondary sexual organs and usually do not take any noticeable part in the rhythmic movements. Movement of the intact swimmerets interfered with recording by shorting the electrodes, especially in the female, and this was largely prevented by removing most of the exopodites and endopodites. Rhythmic movements continued normally following such operations and with little apparent change in frequency. The methods of dissection and preparation of specific motor-fibre bundles in the commissure have been described by Wiersma (1952), and the preparation of primary sensory fibres and interneurones located in the abdominal cord involved in swimmeret movements by Hughes \& Wiersma (1960). In all experiments the preparation was bathed continuously in van Harreveld's solution. Recordings were made from

- On leave of absence from the Department of Zoology, Cambridge, England.

+ Supported by Grant G-5461 of the National Science Foundation. 
the first and second roots or from the connectives between individual abdominal ganglia using micromanipulated platinum electrodes, Tektronix I 12 pre-amplifiers and a Dumont 322 oscilloscope. Ciné films were made using a Ciné Kodak Special $16 \mathrm{~mm}$. camera at speeds of $16-64$ frames/sec., for the loan of which we are greatly indebted to Prof. Albert Tyler.

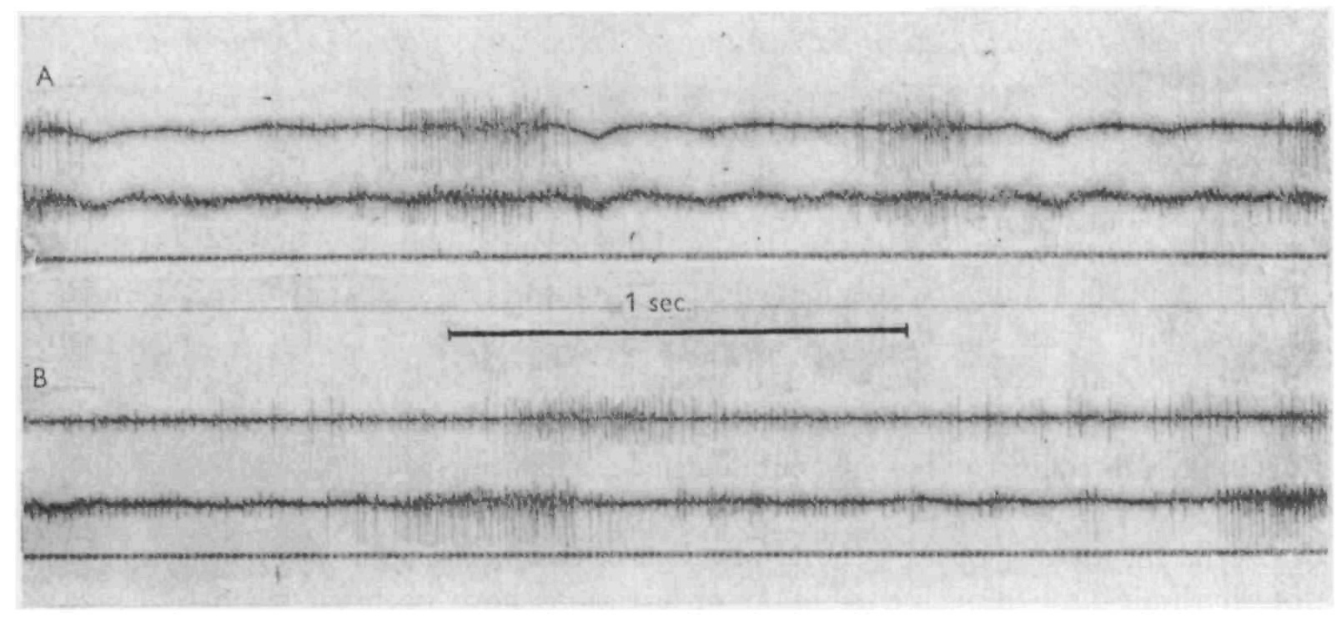

Text-fig. 1. Procambarus clarkii. Isolated abdomen preparation. Electrical recordings of efferent discharges in first roots of the abdominal ganglia. In all cases the roots are cut distal to the electrode. A. Discharges in the first roots of the $5^{\text {th }}$ ganglion. B. Discharges in the ipsilateral first roots of the $4^{\text {th }}$ (upper) and 5 th (lower) ganglia. The main bursts are normally associated with retraction of the swimmeret but subsidiary bursts associated with the protractor movements are visible in some casis (B). Time marker: $(0$ cyc./sec. and I sec.

\section{RESULTS}

(1) Activity in the first roots of the isolated abdomen preparation

When the abdomen of the crayfish is removed from the rest of the body the swimmerets often immediately start well-co-ordinated rhythmical movements which are essentially the same as occur in the intact animal. This is probably caused by the cutting of descending pathways from the brain, of which there are both excitatory and inhibitory ones present as will be discussed below. It was observed that the isolated preparation is more prone to give these movements than are preparations in which the whole C.N.S. is kept intact. The frequency of the movements is between 30 and $60 / \mathrm{min}$. All swimmerets usually become active but sometimes the movements may be restricted to one or two pairs, or to a varying number of swimmerets on one side. An electrode placed under any first root readily picks up rhythmic bursts of impulses which are synchronous with the movements of the swimmeret which it innervates. The bursts persist when the nerve is cut distal to the electrode so that the recorded impulses are then entirely efferent (Text-fig. $\mathrm{x}$ ). These bursts are composed of several units and their timing shows a more or less well-defined pattern, those associated with retraction and protraction of the swim- 
merets being the most easily distinguished. A more detailed pattern is evident, however, and appears to depend on the part of the movement cycle with which a given unit is associated. The main discharge is always connected with retraction, at which time both the number of units involved and the overall frequency are highest. By splitting the first roots, as carried out in some preparations, it has been possible to obtain single unit discharges. In such preparations it is clear that the activities in the individual units grade one into the other rather than that there are distinct instants at which one unit becomes active and another inactive. This agrees with observations on vertebrate motor patterns under similar circumstances (e.g. Weiss, 1941).

Normally the two swimmerets of a segment move together and the discharges recorded in the two first roots of a single ganglion show this expected synchrony, which persists when both roots are cut distally (Text-fig. I A). That this type of co-ordination is not rigid is indicated by the fact that individual swimmerets quite often show movements independent of the contralateral one. It seems possible for the co-ordination to range from a very rigid synchrony, accompanied by very similar nervous discharges in the two roots, to one of almost complete independence. Simultaneous recordings made from first roots of different segments on the same side clearly show the phase relationships between the segments even when the nerve is cut distal to the electrode (Text-fig. I B). The $5^{\text {th }}$ swimmerets nearly always move first and are followed by the others as the wave of excitation spreads forwards. Again, there is no absolute rigidity about the phasing at certain times as is shown, for instance, in Pl. $16, \mathrm{~A}$, which is taken from part of a record in which the $5^{\text {th }}$ swimmerets showed five cycles and the 3 rd only three, but some indication of an abortive burst can be recognized in the root of the 3 rd ganglion. The overall findings suggest that each swimmeret has a centre of its own which is capable of controlling its rhythmic movements and that the coupling of this centre with those of neighbouring ones is not constant but varies in degree and at times can drop below an effective level. Co-ordination between swimmerets on the same side generally seems to be more persistent than that between pairs of the same segment. This preponderance of the ipsilateral co-ordination is also well known in other arthropods, for example, insects (Hughes, 1952).

\section{(2) Recordings from the connectives between two abdominal ganglia}

During some investigations into the function of nerve fibres in the connectives of the abdominal cord, several fibres were encountered which probably play a role in the co-ordination of the beat of the swimmerets. Of first importance is the direct evidence that has been obtained for proprioceptors which detect movements of their basal joints. These are primary sensory fibres which ascend at least across two ganglia (e.g. recording between the $3^{\text {rd }}$ and $4^{\text {th }}$ ganglion, fibres are present which fire when joints of the $5^{\text {th }}$ swimmeret are moved). Each of the joint fibres is usually activated by one particular type of movement, for instance, either by maximal protraction or by retraction, and other fibres have been observed which respond only during separation of the exopodite from the endopodite, as occurs during the 
normal forward movement of the active swimmeret. Interganglionic fibres of another type encountered in the dorsal part of the connective have been described as 'activity' fibres. These fibres fire rhythmically in bursts (Pl. 15, fig. I) when the swimmerets are active, but they are not excited by passive movements of the swimmerets. It seems possible that these recordings are from special fibres concerned in the operation of the basal joint sense organs similar to those described by Alexandrowicz \& Whitear (1957), and Alexandrowicz (1958) for the basal joints of the thoracic appendages of various Crustacea. Such fibres would be connected directly to muscle fibres and could fire especially when this small muscle bundle contracts. It is of interest to note that this type of fibre for the $5^{\text {th }}$ swimmeret was, in contrast to the previous ones, also present in the cord when investigated at the level between the 2nd and $3^{\text {rd }}$ ganglia. Another possibility is that the bursts occur in collaterals of the efferent fibres to the swimmeret. In this way they would transmit a sort of 'efference copy' (von Holst \& Mittelstaedt, 1950) to neighbouring ganglia. There is the additional complication that bursts also occur in interneurones several of which are known to be excited by joint movements of more than one swimmeret. The occasional presence of bursts of impulses without any swimmeret movements ( $\mathrm{Pl}$. I5, fig. I C) is suggestive perhaps of an interneurone.

\section{(3) Progressive isolation of the abdominal cord}

As has been described above, swimmerets of the isolated abdomen show a wellco-ordinated rhythm, and first roots show bursts of impulses which are in the correct phase of the rhythm of movements when the nerve is cut distally. The timing and general pattern of the periodic motor discharges is the same as when the nerve is intact. This offers an opportunity to study the extent to which the timing and nature of first root discharges depend upon the rhythmic inflow from the other ganglia and from the peripheral sense organs. It was found in the first place that cutting any or all second roots of all abdominal ganglia had no influence on the discharges. This might be expected since they are without sensory fibres coming from the swimmerets. Additional cutting of the third roots which are motor to the abdominal flexors did not alter the picture. More significant was the fact that severing the cord between the $5^{\text {th }}$ and 6th ganglia again had no effect by itself or in combination with other cuts. This not only removed the inflow from the many roots of the 6 th ganglion, but also excluded the not unlikely possibility of it being the site of a centre co-ordinating the swimmeret movements. Further isolation of the cord from sensory inflow was effected by cutting first roots, recordings being made from two of them, usually of the $3^{\text {rd }}$ and $5^{\text {th }}$ ganglia on the same side. With the progressive isolation the discharges show increasing changes but a clear rhythm persisted even when only a single root was intact. Pl. I6, C, shows, for instance, recordings made from the roots of the $3^{\text {rd }}$ and $5^{\text {th }}$ ganglia when only the ipsilateral first root of the

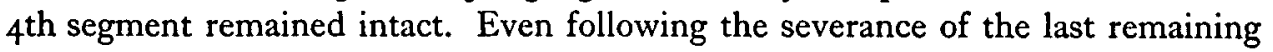
first root the rhythmicity persisted in several preparations. In most cases the greatest similarity recorded before and after cutting of this last root occurs in the period immediately following complete isolation. Later, intermittency may be recorded 
over a range of frequency of about $5-60$ per minute (Text-figs. $2 \mathrm{~B}, \mathrm{D} ; 3^{\mathrm{A}}$ ). In assessing the significance of these observations it is important to remember the variability in the discharge frequency which occurs in the isolated abdominal preparation when all roots remain intact, and especially the fact that rhythmic bursts also become fewer in such preparations as time elapses. But it is equally clear that discharges following complete isolation do not show the same clear patterning of

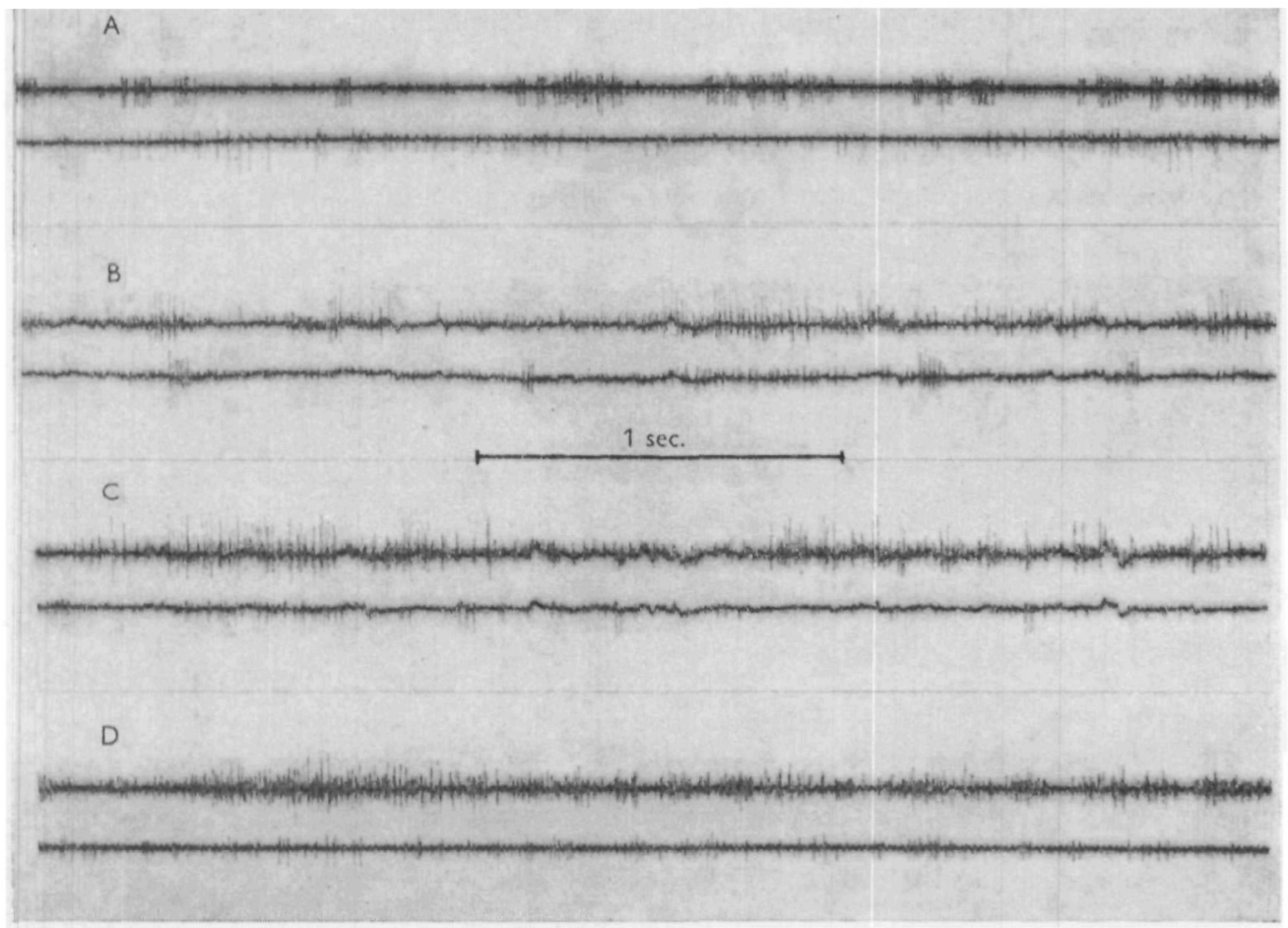

Text-fig. 2. Procambarus clarkii. Isolated abdomen preparation. Activity in first roots of the 4 th (upper beams) and 5 th ganglia following progressive isolation of the abdominal cord. Preparation showing different types of intermittent discharges. Cuts from long records. A. All nerve roots cut except the contralateral first root of the $4^{\text {th }}$ ganglion. Bursts of about $75 / \mathrm{min}$. from $4^{\text {th }}$ ganglion and $25 / \mathrm{min}$. from the $5_{\text {th }}$ ganglion. B. Abdominal ganglia completely isolated. Two types of bursts from $4^{\text {th }}$ ganglion. C. Ten minutes after isolation. Larger bursts become predominant in upper beam (4o/min.) but brief bursts in lower beam. D. Twenty minutes after isolation. Prolonged bursts on upper beam have become less frequent $(4-5 / \mathrm{min}$.). Time marker: I sec.

the individual discharges obtained when the first roots are intact. It seems improbable then, that these intermittent discharges recorded from the isolated nerve cord would be able to produce the finely controlled movements of the swimmerets in the complete absence of any peripheral inflow. On the other hand, they appear directly connected with the movements. In support of this is the fact that the second and third roots show a type of 'spontaneous' activity, which is quite different from that recorded in the first roots. The second roots typically have units 
which discharge continuously (Wiersma, 1952) sometimes with gradual changes in frequency but only very rarely intermittent firing, though there may be a tendency to form doublets (Text-fig. $3 \mathrm{~B}$ ). This indicates that the intermittent bursts in the first roots are not due to anoxia or general deterioration of the preparation as a whole. There can thus be no doubt that within the cord there exists a mechanism capable of showing just the sort of intermittency which is found when all sensory mechanisms are intact. These central mechanisms exist for each of the swimmerets which, as mentioned earlier, are individually capable of independent activity unco-ordinated with their neighbours.

As to the nature of the mechanisms involved in the integration of the activity between different swimmerets, the isolated ganglion preparation is not so helpful. In some cases recordings from first roots of different segments have shown distinct phase relationships when only a single root remained intact, but there were few instances when this was clear in the completely isolated cord. More often the recordings of different roots showed independence from one another, but normal phase relationships were fairly common when the isolated cord was driven from above as is described in the following section.

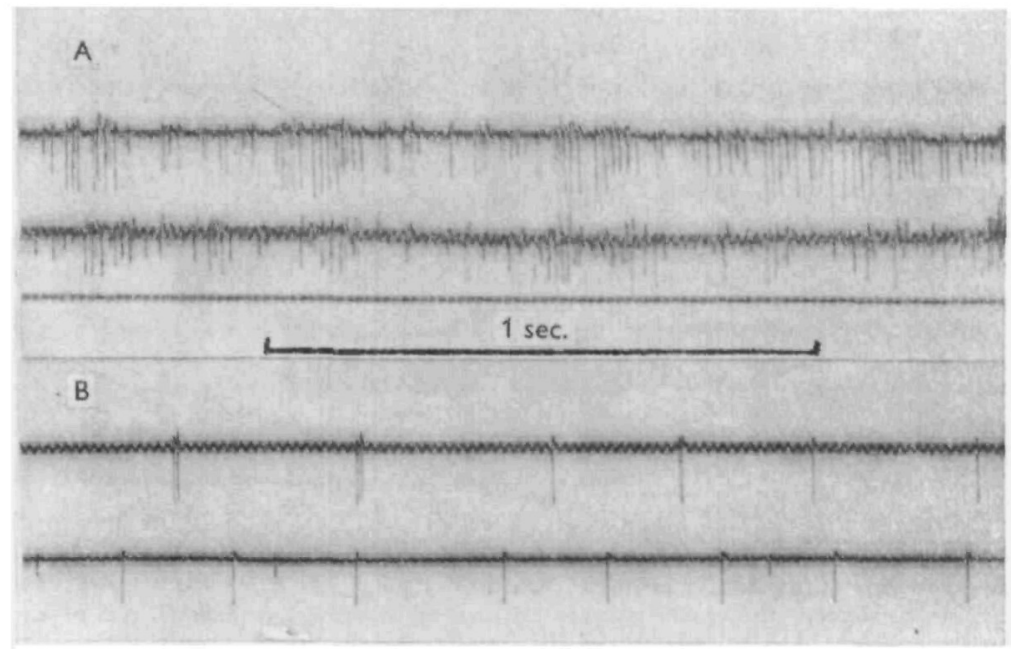

Text-fig. 3. Procambarus clarkii. Isolated abdominal ganglia. A. First root activity from the 4th (upper beam) and $5^{\text {th }}$ ganglia showing rapid intermittency $(120 / \mathrm{min}$.). B. Typical pattern of activity in second roots of the 5 th ganglion. Time marker: $60 \mathrm{cyc} . / \mathrm{sec}$. and $\mathrm{x}$ sec.

\section{(4) The influence of 'higher' centres}

Movements of the swimmerets in the whole animal may be brought about by lifting the walking legs off the ground. Rotation of the animal about its longitudinal axis causes an asymmetry in the activity of the swimmerets and uropods. These reactions, which do not occur in the isolated abdomen, point to a control by the higher nervous centres as does the more persistent rhythmicity after cutting the cord between thorax and abdomen. Direct evidence for the existence of such 


\section{Co-ordination of crayfish swimmerets}

influences has been obtained by stimulating small bundles of nerve fibres in one of the circumoesophageal commissures. Although effects on swimmerets, both excitatory and inhibitory, have been obtained from stimulation of several areas, only one of these was found in almost every preparation and has received special study. Its effects have been analysed with the aid of cine films taken of the resulting movements and also by making records from first root discharges during the stimulation. Because of the similarity of the results in different preparations it seems likely, but not proven, that a single fibre is involved. This fibre is found in the ventral, slightly medial part of the commissure (area 70; Wiersma, 1958). When the small active bundle is stimulated at a frequency of about $50 / \mathrm{sec}$. or higher, the swimmerets immediately move into the fully retracted position, the 5 th swimmeret leading as it does in the next phase in which the swimmerets begin to beat rhythmically with a frequency of $30-60 / \mathrm{min}$. At first these beats consist of only slight returns towards the protracted position, but they gradually become larger. During the stimulation the swimmerets never reach the fully protracted position as is normal in the typical movements. However, after stimulation ceases the beats frequently continue and then often cover the full range of motion. The positions of the exo- and endopodite are also rather different from the 'normal' beat, at least during the stimulation. When the swimmerets are first in the fully retracted position, the exopodite and endopodite separate maximally from each other and stay in this position during the mo rements. Monophasic recordings from first roots during stimulation show a prolonged burst of impulses during the time that the other swimmerets are retracted, which changes into rhythmic bursts when the swimmerets start their rhythmic movements (Pl. 15, fig. 2). Again after discontinuation of the stimulus well-marked intermittent bursts are often present. In two roots of the same side these bursts show the expected phase relationships according to the relative location of the roots. Furthermore, the intermittency is restricted to the first roots and is not shown by efferents in the second or third roots (Pl. 15, fig. 2A).

In the light of the results obtained by the progressive isolation of the abdominal cord it was of interest to follow the same procedure in preparations where driving of the swimmerets was obtained from stimulation of specific areas in the circumoesophageal commissure. In such an experiment it was found that the effect of stimulating area 70 did not change fundamentally when all roots in the abdomen were cut except for the first root innervating a single swimmeret. This swimmeret showed the same typical response as was present before the other roots were cut, and the electrical recordings from two first roots initially cut were also not altered by additional cuttings. The stimulation produced in them a continuous discharge which then became intermittent and persisted after the stimulus was discontinued. It was of considerable interest to find that this driving persisted even when the last remaining root was cut and the abdominal cord became completely isolated from its own peripheral inflow. The intermittent bursts are presumably equivalent to those associated with retraction, and it is of interest that the less intense protractor bursts frequently found before isolation ( $\mathrm{Pl}$. 15, fig. $2 \mathrm{~A}$ ) were very rare in isolated preparations. It is true of course that the C.N.S. was not completely isolated from the 
periphery because stimulation in the commissure also has minor influences on the other appendages, but they do not show rhythmic movements so that it is unlikely that the abdominal cord is subjected to any intermittent sensory input. It is concluded, therefore, that stimulation of these descending pathways with a constant frequency of impulses influences some central mechanisms within the abdominal cord to produce the intermittent discharge of impulses in the complete absence of any sensory feed-back from the appendages, which are normally influenced by these efferent discharges. As we have seen the tendency to produce intermittent discharges is already present in the abdominal nerve cord and the stimulation only seems to accentuate this property. The presence of typical rhythmic movements in the isolated abdomen also precludes the suboesophageal ganglion from being the primary pacemaker. An interesting feature found in several preparations was that the phase relationships of the swimmeret movements and the motor discharges in the cut roots can be the same during 'driving' of the discharges by stimulation of the oesophageal bundle as in the intact animal. Here, too, the $5^{\text {th }}$ swimmeret has the lead, as shown in Pl. I5, fig. 2D, where bursts in the root of the 5 th segment

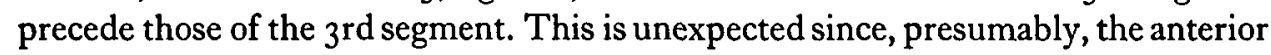
ganglia will be stimulated first by the descending pathways. Since cutting of the 5 th ganglion does not stop the discharges in a more anterior ganglion ( $\mathrm{Pl}$. 1 5 , fig. $2 \mathrm{E}$ ), it is certain that the descending pathways do also have direct connexions with more anterior ganglia. This indicates that the reason for the leading function of the $5^{\text {th }}$ ganglion is its lower threshold, or differently stated, its higher state of central excitation.

An illustration of the relative independence of the individual centres for swimmeret movements may also be seen in Pl. 15, fig. 2E, where rhythmicity is clearly

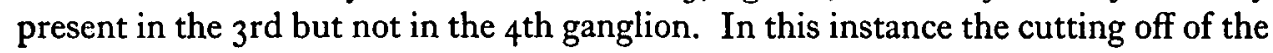

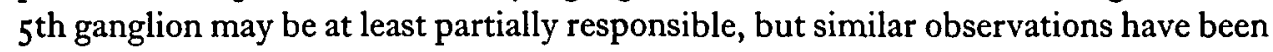
made when the whole abdominal cord was still intact, though these are rare.

Variations in the frequency of stimulation produced differences in both the observed activity of the swimmerets and the nature of electrical activity in the first roots. At low frequencies $(5-\mathrm{ro} / \mathrm{sec}$.) no movements were detectable, but a very slight increase in impulse discharge occurred in the first roots. Over a narrow range of frequency $(c .30 / \mathrm{sec}$.) slight twitches could be seen in the swimmerets and evidence for direct driving of units in the first roots at the stimulation frequency was observed. Raising the frequency now produced the increased discharge in the roots associated with the tonic backwards movements of the swimmerets followed by intermittent bursts which persisted when stimulation was discontinued. The frequency of these bursts did not appear to be influenced by further increases in frequency, although the initial discharge was increased and the rate of the swimmeret retraction was more rapid.

In marked contrast to the gradual development of the swimmeret beats on stimulation of the fibre from area 70 , it was noted that continuous stimulation of a fibre in area 64 caused an immediate rhythmic beating quite like spontaneous metachronic waves. Probably because of the presence of an inhibitory interneurone in 
the immediate neighbourhood of this fibre, it has been prepared successfully in only very few preparations, and hence no definite statements can as yet be made about the root discharges and the order in which the swimmerets beat under different circumstances when this fibre is stimulated. In addition to these observations on the release of intermittent discharges in the first roots of the abdominal cord clear evidence has been found for the existence of inhibitory and excitatory effects on single units in the first roots by stimulation of other fibres or small bundles in the oesophageal commissures. For instance, Text-fig. $4 \mathrm{~A}$ shows the excitatory effect on a tonically discharging unit when stimulation was applied to a small bundle in area $72 / 74$ of the commissure. In this particular example the root was
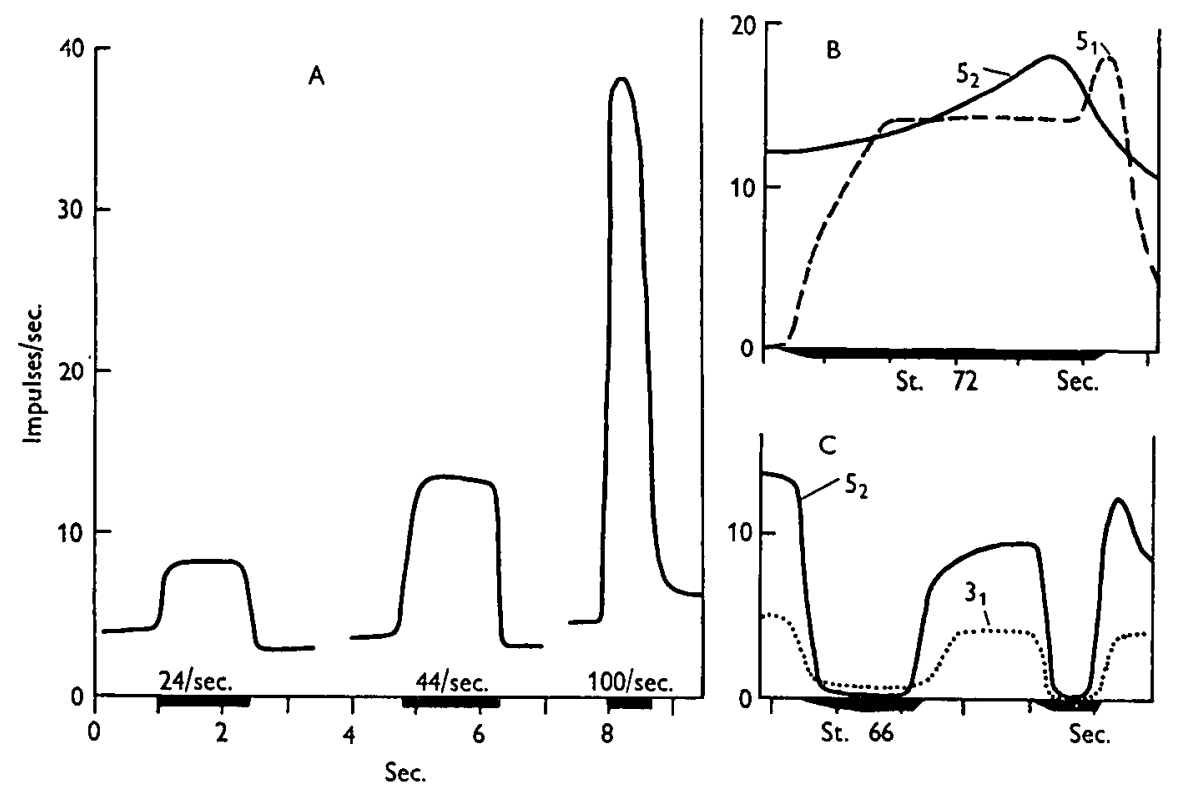

Text-fig. 4. Procambarus clarkii. Abdominal nerves intact except those from which recordings are shown. A. Effect of stimulating a small bundle of fibres in area $72 / 74$ of the circumoesophageal commissure at different frequencies on the discharge of impulses in a single unit of the contralateral first root of the 3 rd ganglion. B. Impulse frequency in two units of the ipsilateral first root of the $5^{\text {th }}$ ganglion following stimulation $(50 / \mathrm{sec}$.) of a bundle in area 72 . C. Same preparation as $B$, stimulation in area 66 produces inhibition of units in the first root of the 3 rd and 5 th ganglia.

on the contralateral side but similar effects are found in ipsilateral roots also. It will be seen that the frequency of discharge is clearly related to that of the stimulus in this instance, but this is not always quite so clear. The excitatory effect of stimulating

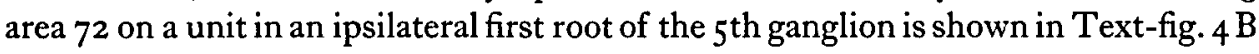
whereas another unit $\left(5_{2}\right)$ is not so much affected. On the other hand, the latter unit is very strongly inhibited by stimulation of a bundle in area 66 , as was another

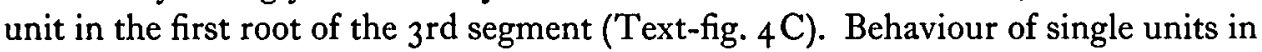
another preparation following stimulation of a bundle between areas 70 and 72 is

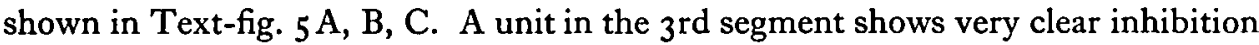


whereas another unit in the same root $\left(3_{2}\right.$, Text-fig. 6$)$ and also one in the $5^{\text {th }}$ segment shows a slight excitatory effect during the stimulus with a very pronounced increase in discharge frequency when the stimulation is stopped. In record C (Textfig. 5) this resulted in rhythmic intermittent bursts in these units as the swimmerets were excited and then units in the two roots were out of phase (Text-fig. 6).

Although examples of these types of influence from the brain could be found in most preparations, it was difficult to repeat a particular response consistently in several preparations (with the exception of the effects on the swimmerets from area
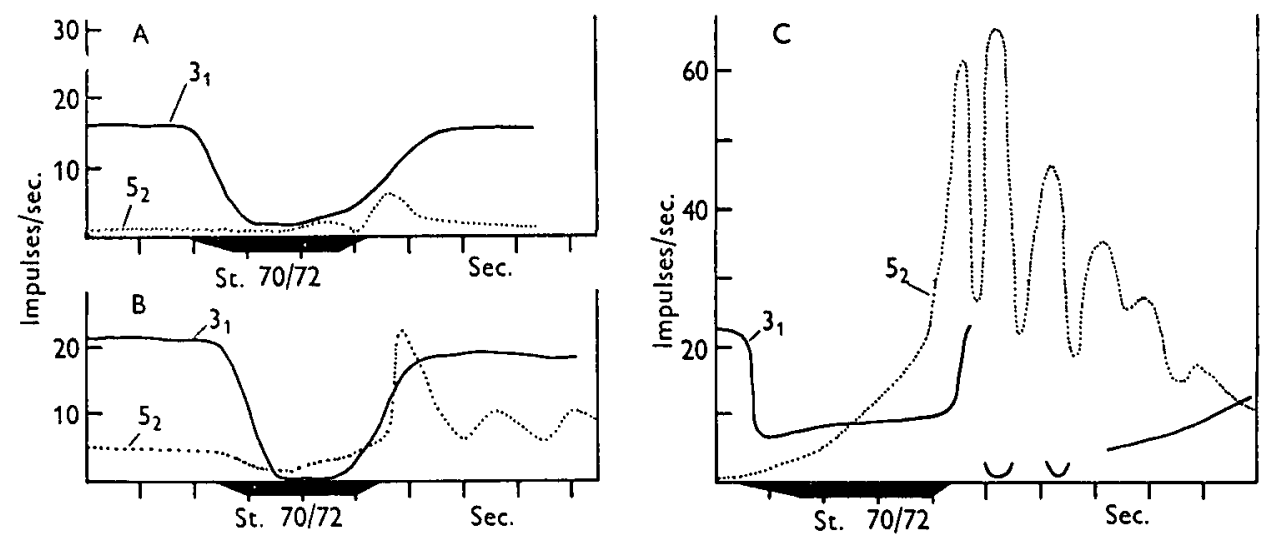

Text-fig. 5. Procambarus clarkii. Abdominal nerves intact except those from which recordings are shown. Changes in frequency of impulses in two units $\left(3_{1}\right.$ and 52$)$ from the ipsilateral first roots of the $3^{\text {rd }}$ and $5^{\text {th }}$ ganglia produced by stimulation of a bundle of fibres in area $70 / 72$ of the circumoesophageal commissure. The frequency of stimulation was $50 / \mathrm{sec}$. in all cases and the intensity was raised gradually in each experiment, but maintained at a constant level for about 2 sec. The three graphs (A, B and C) show the effect of progressively increasing this final intensity.

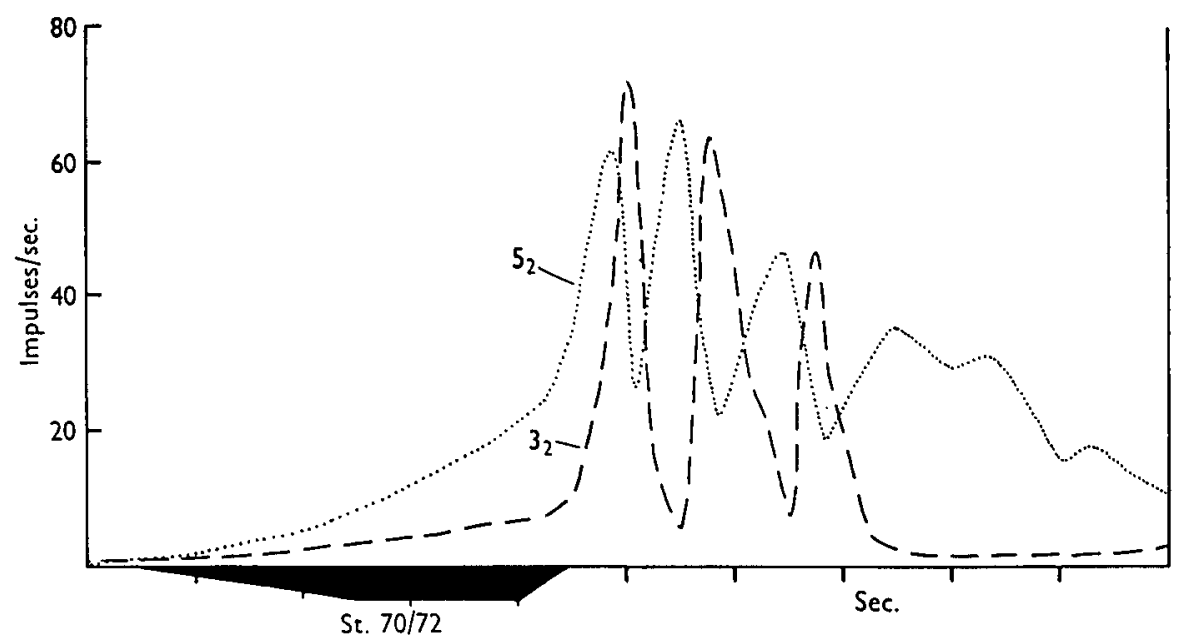

Text-fig. 6. Procambarus clarkii. Same experiment as Text-fig. ${ }_{5}$ C. Rhythmic changes in the frequency of single units in the first roots of the 3 rd and 5 th ganglia following stimulation (50/sec.) of a small bundle in area $70 / 72$. 
70 reported above). Moreover, variability was encountered in the effects of stimulating the same bundle in a given preparation. It was for this reason that the investigations were not carried further, but the results obtained undoubtedly give objective evidence for pathways by which the brain can exert the excitatory and inhibitory effects which have been ascribed to it on many occasions.

\section{DISCUSSION}

The observations described above are of interest in relation to the much-discussed problem of whether rhythmic movements are primarily due to occurrences in the C.N.S. or are triggered by peripheral sensory inflow. Rhythmic electrical activity in the deafferentated C.N.S. has been considered as favouring the first viewpoint (Adrian, I93 I; von Holst, 1937). On the other hand, evidence has been obtained that in order to make co-ordinated limb movements possible, at least one limb must have both afferent and efferent innervation intact (Gray, 1950) and a similar finding was made with respect to the leech, in which rhythmic electrical discharges were present in the cord as long as a limited region of the body was connected to it, whereas after isolation of the cord no comparable rhythmicity obtained (Gray, Lissman \& Pumphrey, I938). Our results on the isolated abdomen are in fairly good agreement with this latter view, for the rhythmic discharges which can be led off from a preparation with only a single first root intact are essentially similar to those of the intact cord; but this is not true when this last remaining root is severed. It is thus evident that proprioceptive impulses are of importance for normal coordination of the swimmerets under these conditions. However, a certain rhythmicity can still be present in the spontaneous discharges even in the totally isolated cord. Since such discharges are absent from the other roots, which do not innervate the swimmerets, and since the discharges in the first roots, though greatly changed from those during regular beating, are still like those which can normally occur when the swimmerets are not well co-ordinated, it appears that they do represent abortive attempts at rhythmic swimmeret movements. This view is greatly strengthened by the fact that stimulation of certain central nerve fibres is capable of inducing quite regular and normal-looking rhythmic discharges in preparations where the abdominal cord is totally isolated from the periphery but connected to the higher part of the C.N.S. In this connexion it was of special interest to note that different central fibres exert different types of control, which are, however, independent of sensory inflow in the cord. Stimulation of the fibre in area 70 , which was the most extensively investigated area, gives rise to a series of reactions, namely, first retraction and spreading of the rami and then gradually increasing movements of the swimmerets. It might have been expected that especially the second part of this sequence would depend on the local sensory inflow. However, this was obviously not the case, since after complete isolation the impulse outflow in the first roots retained its pattern of firing, uninterruptedly at first and in more and more pronounced bursts later. Though we succeeded only very few times in obtaining the fibre from area 64 , the effect of its stimulation was also independent of the presence of local sensory inflow. 
From these results we are inclined to conclude that, though sensory inflow from the swimmerets plays an important role in locally elicited rhythmic movements, it is without much importance for centrally driven rhythms. Whether or not the latter are to be considered as reacting to sensory stimuli, for example, from the head or thorax, or may fire 'spontaneously' is unknown. In this instance there can thus be no sharp distinction between a totally spontaneous action and one dependent on sensory input. But it is certain that the same typical metachronal movements of the swimmerets can be elicited in different ways, namely, by a local co-ordinating mechanism in the cord, in which sensory input plays an important part, and by specific 'regulatory' nerve fibres from the brain, for which no other sensory input is necessary. In addition the brain can, by a similar mechanism, inhibit the swimmeret movements. The whole mechanism of the nervous control of the swimmeret movement reminds one strongly of that in the neurogenic heart ganglion of the decapods (Wiersma \& Novitski, 1942; Maynard, 1955; Bullock \& Terzuolo, 1957). Whereas in the heart ganglion single cells may show individual spontaneity, as they do in the centres of each swimmeret, there is in the abdominal cord, in addition, a co-ordination between the different ganglionic centres, which is still weaker. Even during central driving it was noticed that not all swimmerets need to give the same number of beats, though this is more often the case than when the cord is isolated.

As a hypothesis, the following picture may be proposed. (a) Each local ganglion contains a centre of co-ordination for each swimmeret. Local sensory inflow will tend to impress a certain pattern of rhythmicity into the firing order and firing frequency of the different motor neurones, which leads to a full swimmeret 'stroke'. However, any variation can occur, related to the 'activity state' of the centre. (b) Interconnexions between the different centres exist, which show a delay time accounting for the tendency of anterior swimmerets to beat later than posterior ones. It is likely that usually the last pair of swimmerets (normally the ${ }_{5}$ th) has the strongest influence in this respect. It is uncertain whether similar connexions in a posterior direction are present, though there are reflex connexions in this direction (this was shown by the fact that pushing the 2nd swimmeret backward may trigger swimming movements, especially on the ipsilateral side). (c) There are interneurones coming from the brain, which by continuously firing impulses can trigger the centres of the swimmerets to rhythmic firing. This may be based on the increased 'activity state' which they bring about. (d) Conversely there are interneurones which stop swimmeret movements, presumably by decreasing the activity state.

In view of the fact that the single heart ganglion does not readily yield to a full analysis of the underlying events (Bullock \& Terzuolo, 1957) it is not likely that the many mutual influences which are present in the abdominal cord can be completely analyzed. But the 'release' of a motor pattern through the stimulation of central interneurones is strongly indicated as the most likely explanation for swimmeret movements. This release can also be brought about by sensory input of local nature. 


\section{SUMMARY}

1. Electrical activity recorded in the first roots of the abdominal nerve cord show bursts of activity which accompany rhythmic movements of the swimmerets. These bursts persist when a root is cut distal to the electrodes.

2. Proprioceptive impulses have been recorded from the distal portion of these nerves during passive movements of the swimmerets. They have also been recorded in the connectives during both passive and active movements.

3. Cutting all second and third roots of the abdominal ganglia does not interfere with the rhythmic swimmeret movements of the isolated abdomen. Rhythmic efferent bursts persist in first roots even when only a single first root remains intact in such a preparation.

4. Intermittent bursts are also found in the first roots of a completely isolated cord but their pattern, frequency and phase relationships differ from those recorded in the same roots before isolation was completed. Such bursts are very rare in second and third roots.

5. Stimulation of small bundles of fibres in the circumoesophageal commissure produces well-defined inhibitory and excitatory effects on the discharge of single units in the first roots.

6. One specific bundle found in many preparations, when stimulated at $5 \% / \mathrm{sec}$., caused a tonic retraction of all the swimmerets which then began to beat rhythmically and continued to do so when stimulation was discontinued.

7. Intermittent bursts in the first roots took place with correct phasing during this stimulation even when the abdominal ganglia were isolated except for their connexion with the last thoracic ganglion. Again, such bursts were absent in the second and third roots.

8. It is concluded that both the inflow from peripheral proprioceptors and intrinsic properties of the central ganglia play essential parts in the co-ordination of the metachronal movements of the swimmerets.

\section{REFERENCES}

Adrian, E. D. (1931). Potential changes in the isolated nervous system of Dytiscus marginalis. F. Physiol. 72, 132-5I.

Alexandrowicz, J. S. (1958). Further observations on proprioceptors in crustacea and a hypothesis about their function. F. Mar. Biol. Ass. U.K. 37, 379-96.

Alexandrowicz, J. S. \& Whitear, Mary (r957). Receptor elements in the coxal region of Decapoda Crustacea. F. Mar. Biol. Ass. U.K. 36, 603-28.

Bullock, T. H. \& Terzuolo, C. A. (1957). Diverse forms of activity in the somata of spontaneous and in tegrating ganglion cells. $\mathcal{F}$. Physiol. 138, 341-64.

Gray, J. (1950). The role of peripheral sense organs during locomotion in the leech. $\mathcal{F}$. Exp. Biol. r5, 408-30.

Gray, J., Lissmann, H. W. \& Pumphrey, R. J. (1938). The mechanism of locomotion in the leech. F. Exp. Biol. 15, 408-30.

voN Holst, E. (1937). Vom Wesen der Ordnung im Zentralnervensystem. Naturwissenschaften, 25, 625-3I, 64I-47.

von Holst, E. \& Mittelstaedt, H. (1950). Das Reafferenzprinzip (Wechselwirkungen zwischen Zentralnervensystem und Peripherie). Naturwissenschaften, 37, 464-76.

Huches, G. M. (1952). The co-ordination of insect movements. I. The walking movements of insects. F. Exp. Biol. 29, 267-84. 
Hughes, G. M. \& Hickey, G. Cinematographic analysis of movements of the crayfish, Procambarus clarkii (Girard). (In preparation.)

Hughes, G. M. \& WIERSMA, C. A. G. (1960). Neuronal pathways and synaptic connexions in the abdominal cord of the crayfish. F. Exp. Biol. 37, 291-307.

Maynard, D. M. (1955). Activity in a crustacean ganglion. II. Pattern and interaction in burșt formation. Biol. Bull., Woods Hole, rog, 420-36.

Prosser, C. Ladd (1935). Action potentials in the nervous system of the crayfish. III. Central responses to proprioceptive and tactile stimulation. F. Comp. Neurol. 62, 495-505.

WeIss, P. (1941). Self-differentiation of the basic patterns of coordination. Comp. Psychol. Monogr. 17, No. 4, 1-96.

WiERSMA, C. A. G. (1952). Repetitive discharges of motor fibres caused by a single impulse in giant fibres of the crayfish. F. Cell. Comp. Physiol. 40, 399-420.

Wiersma, C. A. G. (1958). On the functional connexions of single units in the central nervous system of the crayfish, Procambartus clarkii (Girard). F. Comp. Neurol. 110, 421-72.

Wiersma, C. A. G. \& Hughes, G. M. (196r). On the functional anatomy of neuronal units in the abdominal cord of the crayfish, Procambarus clarkii Girard. F. Comp. Neurol. (in the press).

Wiersma, C. A. G. \& Novitski, E. (1942). The mechanism of the nervous regulation of the crayfish heart. F. Exp. Biol. 19, 255-65.

\section{EXPLANATION OF PLATES}

\section{Plate 15}

Fig. I. Procambarus clarkii. Isolated abdomen preparation. Electrical recordings from small bundles of fibres in the right connective between the $3^{\text {rd }}$ and $4^{\text {th }}$ ganglia. For position of areas see Wiersma \& Hughes ( $196 \mathrm{I}$ ). A. Area 76 . Discharges particularly associated with retractor movements of the $4^{\text {th }}$ and $5^{\text {th }}$ pairs of swimmerets. Tonic discharge occurs in the same units when these swimmerets were in a partially retracted position. Cutting of this bundle produced retraction particularly in the ipsilateral 4 th swimmeret. B. Area 76 . Similar record from another preparation. C. Area 8o. Bursts not apparently associated with any rhythmic swimmeret movements. Time marker : $60 \mathrm{cyc} . / \mathrm{sec}$. and $\mathrm{x}$ sec.

Fig. 2. Procambarus clarkii. Recordings of efferent impulses in abdominal roots during and following stimulation (about $5 \% /$ sec., indicated by arrows) of small bundles in the circumoesophageal commissure. A. Intact preparation showing difference between first root (upper beam) and second root activity following stimulation of area 72 . B. Intact preparation; activity in first roots of 3 rd (upper beam) and 5 th ganglia. Stimulation of area 70 in the ipsilateral commissure. C. Faster recording of intermittent bursts in first roots of the 3 rd and 5 th ganglia of an intact preparation. Stimulation of area 70/72. D. Same preparation as $\mathrm{B}$ but all segmental nerves of abdominal ganglia $1-5$ severed and connectives between 5 th and 6 th ganglia cut. E. Same preparation as B and D. $5^{\text {th }}$ ganglion now removed. Recordings from first roots of $3^{\text {rd }}$ (upper beam) and $4^{\text {th }}$ ganglia.

\section{Plate 16}

Procambarus clarkii. Isolated abdomen preparation. All second and third roots and connectives between 5 th and 6th ganglia severed. Recordings of activity in first roots of the 3 rd (upper beams) and 5 th ganglia cut distal to the electrodes. Cuts from long records. A. All first roots intact except those from which recordings are made. B. All first roots cut except those of the 4th ganglion. C. Only ipsilateral first root of $4^{\text {th }}$ ganglion intact. D. Same preparation as B but all segmental nerves of abdominal ganglia $\mathrm{I}-5$ severed and connectives between 5 th and 6 th ganglia cut. E. Same preparation as B and D. 5th ganglion now removed. Recordings from first roots of $3^{\text {rd }}$ (upper beam) and $4^{\text {th }}$ ganglia. 
A

B
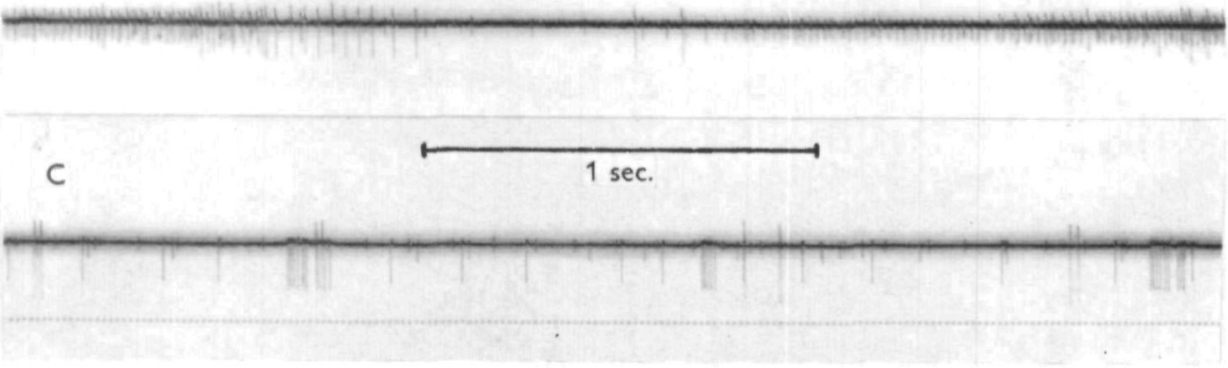

Fig. I

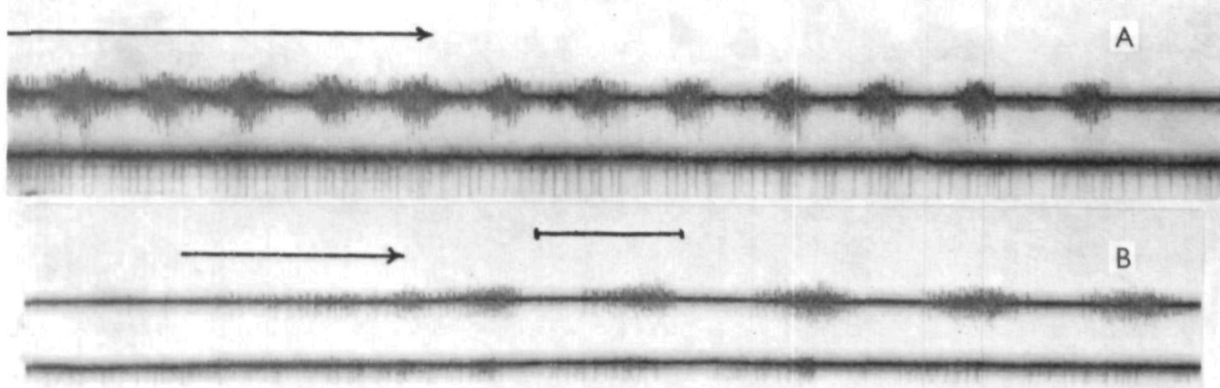

C

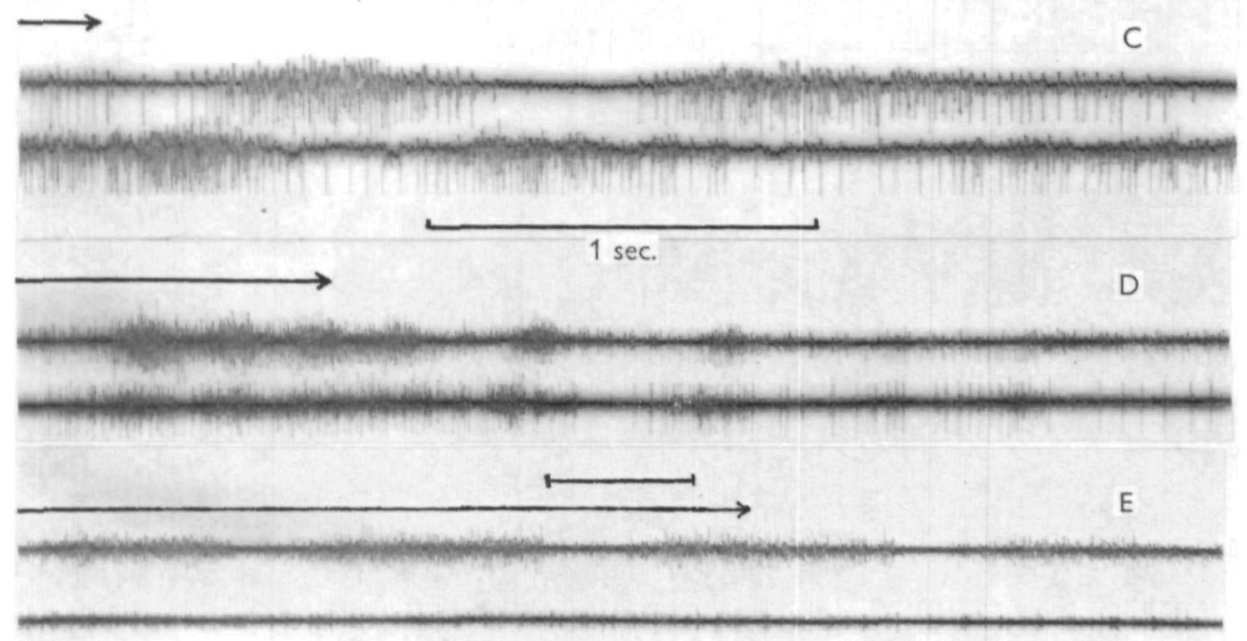

Fig. 2

HUGHES AND WIERSMA-THE CO-ORDINATION OF SWIMMERET MOVEMENTS IN THE CRAYFISH, PROCAMBARUS CLARKII (GIRARD) 


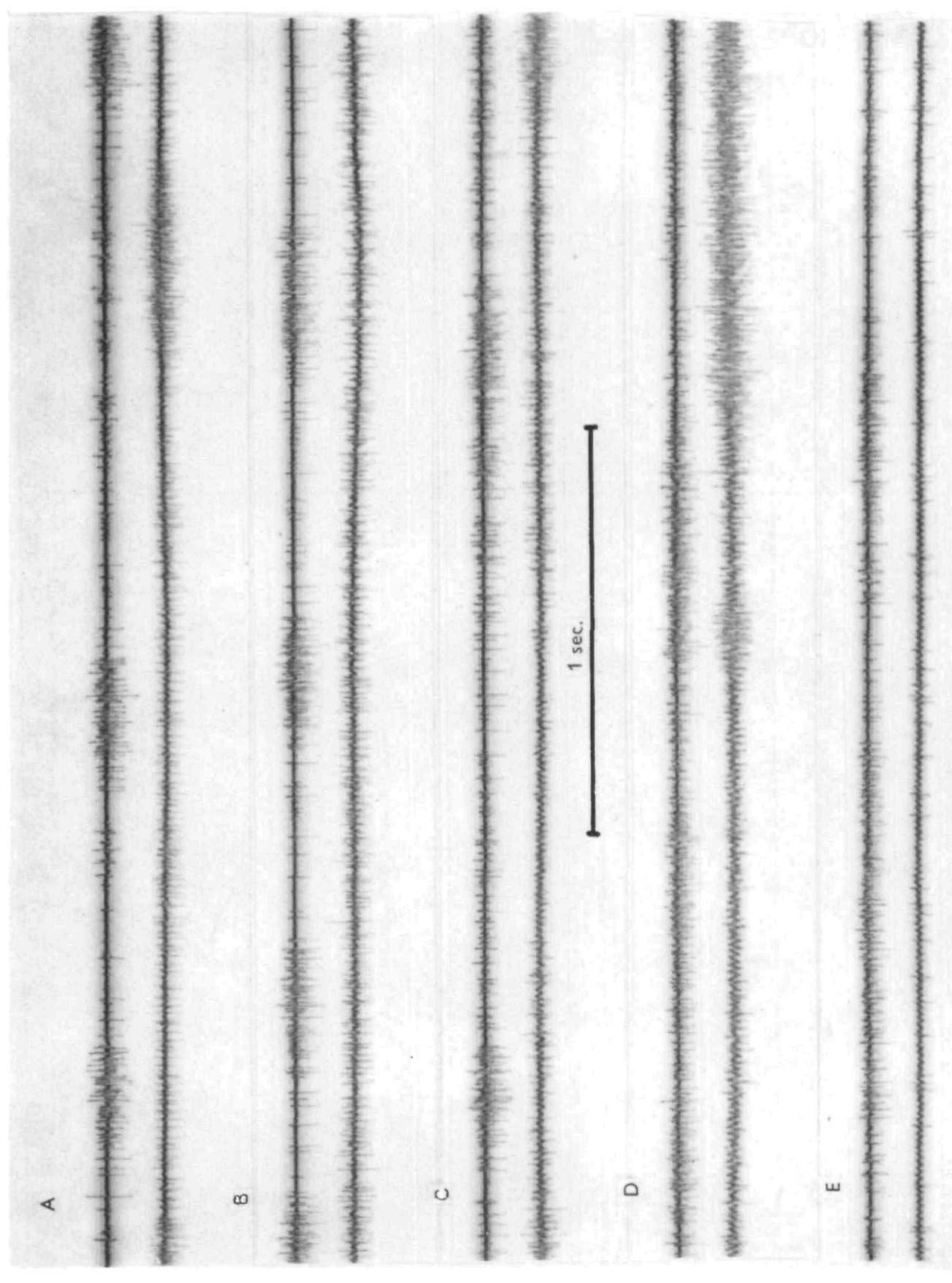

HUGHES AND WIERSMA-THE CO-ORDINATION OF SWIMMERET MOVEMENTS IN THE CRAYFISH, PROCAMBARUS CLARKII (GIRARD) 